\title{
The Ride-Hailing Services: An Empirical Study among Private University Students in Klang Valley, Malaysia.
}

Jee Fenn Chung, Akram Abdulraqeb Sultan Al-Khaled

To Link this Article: http://dx.doi.org/10.6007/IJARBSS/v10-i12/8224

DOI:10.6007/IJARBSS/v10-i12/8224

Received: 12 October 2020, Revised: 16 November 2020, Accepted: 29 November 2020

Published Online: 21 December 2020

In-Text Citation: (Chung \& Al-Khaled, 2020)

To Cite this Article: Chung, J. F., \& Al-Khaled, A. A. S. (2020). The Ride-Hailing Services: An Empirical Study among Private University Students in Klang Valley, Malaysia. International Journal of Academic Research in Business and Social Sciences, 10(12), 769-785.

\section{Copyright: @ 2020 The Author(s)}

Published by Human Resource Management Academic Research Society (www.hrmars.com)

This article is published under the Creative Commons Attribution (CC BY 4.0) license. Anyone may reproduce, distribute, translate and create derivative works of this article (for both commercial and non-commercial purposes), subject to full attribution to the original publication and authors. The full terms of this license may be seen at: http://creativecommons.org/licences/by/4.0/legalcode

\section{Vol. 10, No. 12, 2020, Pg. 796 - 785}

Full Terms \& Conditions of access and use can be found at http://hrmars.com/index.php/pages/detail/publication-ethics 


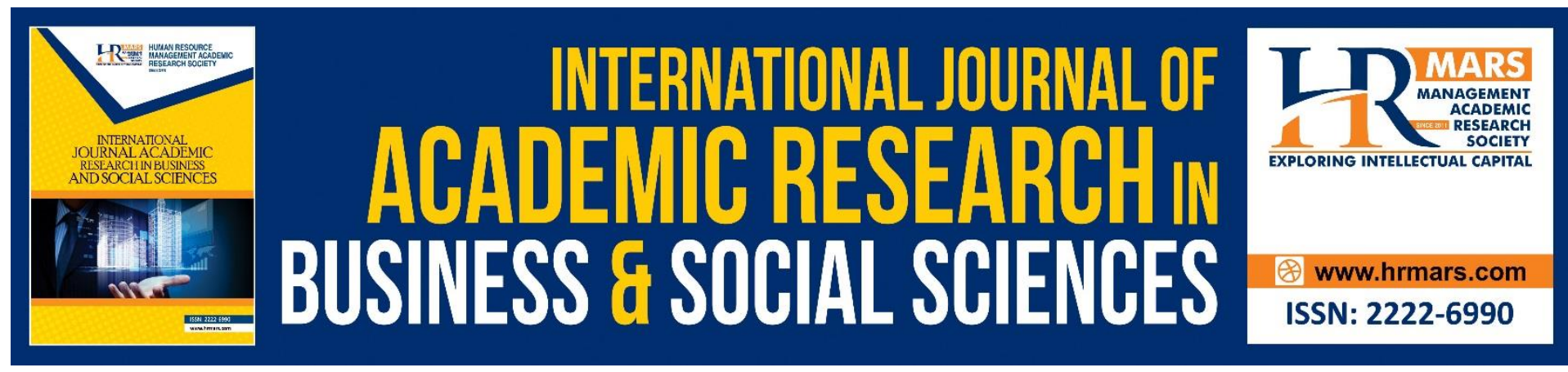

\title{
The Ride-Hailing Services: An Empirical Study among Private University Students in Klang Valley, Malaysia.
}

\section{Jee Fenn Chung, PhD, Akram Abdulraqeb Sultan Al-Khaled, $\mathrm{PhD}$}

Associate Professor and Head-Centre of Institutional Research, Berjaya University College, Malaysia, Senior Lecturer, Faculty of Business, Berjaya University College, Malaysia.

Email: chung.jeefenn@berjaya.edu.my

\begin{abstract}
This study was carried out in order to examine the relationship between tangible, reliability, comfort, price, promotion and the demand for ride-hailing services among private university students in Klang Valley, Malaysia. By using purposive sampling method, a total of 383 private university students participated in this study. The Descriptive Analysis and Inferential Analysis were administrated in analysing the relationship between tangible, reliability, comfort, price, promotion and the demand for ride-hailing services. As a result, this study revealed that there was a high degree of demand for ride-hailing services among private university students in Klang Valley, Malaysia. There was significant difference on the demand for ride-hailing services in accordance with gender, nationality, family monthly income and marital status respectively. However, no significant difference was found for the aspects of age groups and the level of studies. Correlation Analysis showed significant relationships between tangible, reliability, price, promotion and the demand of ride-hailing services. However, there was no significant relationship found between comfort and the demand for ride-hailing services. Regression Analysis showed that all the factors studied contributed $55.9 \%$ in variant change on the demand for ride-hailing services. Furthermore, this study also found that reliability is the most dominant predictor factor of the demand for ride-hailing services. Besides, tangible, price and promotion found to be good predictor factors too. These findings contributed to the existing literature and conceptual link on the relationship between tangible, reliability, comfort, price, promotion and the demand for ride-hailing services. The results of this study are crucial for ride-hailing services providers on placing a significant emphasis on several suggested strategic plans to improve the demand for ride-hailing services. Several recommendations were also provided for the interests of future studies in this area.
\end{abstract}

Keywords: Ride-hailing Services, Service Quality, Private University Students, Malaysia.

\section{Introduction}

According to Allied Market Research, the global ride-hailing services market is predicted to expand from US\$36.5bil in 2017 to US\$126.5bil by 2025 (Pranav \& Akshay, 2018). In the related development, The Star (2019) reported that the global ride-hailing services market is 
expected an upward growing trend of $16.5 \%$ in 2019 to a higher rate in 2020. Indeed, ridehailing services have grown to become a multi-billion dollar industry. Today, ride-hailing services are set to grow even larger, as increasingly more people are turning to online and app-enabled platforms to solicit rides to get around cities, thanks to the convenience and the transparent and competitively priced fees that the services offer. Internationally, Uber, Grab, Lyft and Didi are some of the key players operating in the ride-hailing, or sometimes called ehailing, services market (Kosoff, 2015).

In Malaysia, the ride-hailing services have grown rapidly, especially in the intense populated cities such as Kuala Lumpur, Putrajaya, Petaling Jaya, Sham Alam, etc. (Pradhan, 2019). Grab is the dominant service provider. Other players such as MyCar, Mula, Ezcab, Riding Pink and Gojek are set to heat up the country's ride-hailing services market.

Apparently, ride-hailing services provide convenient and affordable mode of transportation for everybody; especially those are always on the move such as university and college's students. However, the lack of research attention given to the ride-hailing services among university students in Malaysia in the previous studies highlights a significant research gap that requires further investigation.

\section{Objective of the Study}

-To examine the relationship between tangible, reliability, comfort, price, promotion and the demand for ride-hailing services among private university students in Klang Valley, Malaysia.

\section{Research Questions}

This study is conducted with the intention to address the following research questions:

i. What is the level of demand for ride-hailing services among private university students in Klang Valley, Malaysia?

ii. Is there any difference on the demand of ride-hailing services in accordance with the private university students' demographic backgrounds?

iii. Is there any significant relationship between tangible, reliability, comfort, price, promotion and the demand for ride-hailing services among private university students in Klang Valley, Malaysia?

\section{Literature Review and Hypotheses Development Service Quality}

Conceptually, scholars in the Consumers Behavioural Theory believed that the purchase intention of a product or service is strongly linked with service quality (Loudon \& Della Bitta, 1993; Parasuraman et al., 1985; Kassarjian, 1982; Howard \& Sheth, 1969). According to Parasuraman et al (1985)'s SERQUAL Model, service quality is "disconfirmation" paradigm which derived from the customer satisfaction model whereby an outcome is from the customer pre expectations from actual performance perceived from the products and services. Literately, good service quality will lead to positive purchase intention of a product or service. Nevertheless, there is lack of research study on service quality dimensions related to ride-sharing services in Malaysia. In this study, the researcher selected two of the service quality dimensions, i.e. tangible and reliability and three other factors, i.e. comfort, price and promotion to examine their relationship with the demand for ride-hailing services among Malaysian private university students. 


\section{Tangible and the Demand for Ride-Hailing Services}

According to Parasuraman et al (1991), tangible refers to a person's appearance, physical facilities like settings, decorations, display, and equipment. Zeithaml et al (2018) added that tangible like the safety and convenience for customers and it representative as company's image and quality. Relatively, in the past five years, studies conducted by researchers such as Pradhan (2019), Pranav and Akshay (2018), Balachandran \& Hamzah (2017), Sakunlertvattana (2016), and Kosoff (2015) found positive significant relationship between tangible and the demand for ride-hailing services. Therefore, $\mathrm{H}_{1}$ is derived as follow:

$\mathrm{H}_{1}$ : Tangible is positively related to the demand for ride-hailing services

\section{Reliability and the Demand for Ride-Hailing Services}

McKnight et al (1985) conceptualised reliability in the transportation services as the ability to execute the service with consistency and reliable. In ride-hailing services, the aspects related to reliability include punctuality, waiting time, arrival at destination, journey length, communications, and scheduled routes. Recent studies conducted by Nguyen-Phuoc et al. (2020), Ma et al. (2019), Wang et al. (2018), Balachandran and Hamzah (2017), and Feng et al. (2017), found that reliability as one of the factors that positively associated with the demand for ride-hailing services. Hence, $\mathrm{H}_{2}$ is derived as follow:

$\mathrm{H}_{2}$ : Reliability is positively related to the demand for ride-hailing services

\section{Comfort and the Demand for Ride-Hailing Services}

According to Litman (2008), service comfort in the transportation sector refers to the availability and quality offered by the service provider such as the seats, space, journeys, air conditioning, etc. Theoretically, scholars agreed that comfort is one of the factors influences customer's decision making on the purchase of a product or service (Loudon \& Della Bitta, 1993; Parasuraman et al., 1985; Kassarjian, 1982; Howard \& Sheth, 1969).

Studies conducted by Nguyen-Phuoc et al. (2020), Ma et al. (2019), Wang et al. (2018), Balachandran and Hamzah (2017), Waruwu and Adhiutama (2017), revealed that comfort is positively correlated with the demand for ride-hailing services. Therefore, $\mathrm{H}_{3}$ for this study is developed as follow:

$\mathrm{H}_{3}$ : Comfort is positively related to the demand for ride-hailing services

\section{Price and the Demand for Ride-Hailing Services}

Price is a vital aspect in the ride-hailing services which affecting the affordability between services provided and fares charged. Conceptually, price is significantly influenced the purchase intention of ride-hailing services (Kotler \& Armstrong, 2012). In fact, price element in service industry is indicated as the most important factor, influencing the level of consumers satisfaction, and eventually, affect their re-purchase intention because if consumers estimate the value of obtained service, they usually think of price (Virvilaite et al., 2009). Previous studies carried out by Assegaff and Pranoto (2020), Nguyen-Phuoc et al. (2020), Prabowo (2018), Wang et al. (2018), Balachandran and Hamzah (2017), Septiani et al. (2017), and Feng et al. (2017), showed that price is positively correlated with the demand for ride-hailing services. Therefore, hypothesis $\mathrm{H}_{4}$ is developed as follow:

$\mathrm{H}_{4}$ : Price is positively related to the demand for ride-hailing services 


\section{Promotion and the Demand for Ride-Hailing Services}

According to Lovelock and Wright (2002), promotion is to persuade the target market on how the consumer makes decision to purchase a product or service. Conceptually, promotion activities influence customer's thinking, emotions while purchasing the products or services (Kotler \& Armstrong, 2012). Recent research found that there is a strong and positive relationship between promotion and the demand for ride-hailing services (Nguyen-Phuoc et al., 2020; Pradhan, 2019; Prabowo, 2018; Balachandran \& Hamzah, 2017). Hence, $\mathrm{H}_{5}$ for this study is derived as follow:

$\mathrm{H}_{5}$ : Promotion is positively related to the demand for ride-hailing services

\section{Conceptual Framework}

Figure 1 shows the conceptual framework for this study. Tangible, reliability, comfort, price and promotion served as the independent variables, while, the demand for ride-hailing services is the dependent variable.

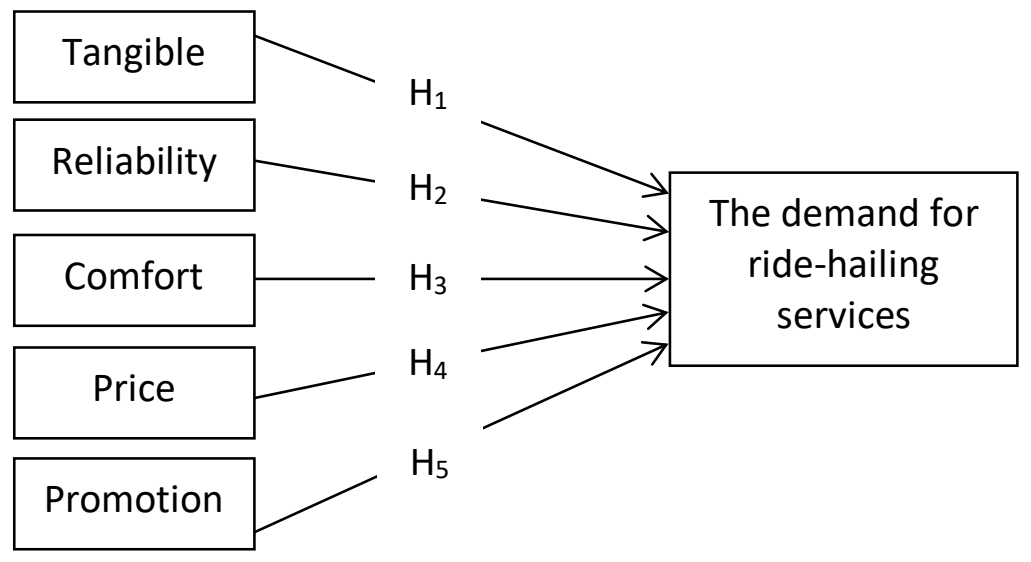

Figure 1: Conceptual Framework

(Source: Adapted from Nguyen-Phuoc et al., 2020; Balachandran \& Hamzah, 2017; Sakunlertvattana, 2016)

\section{Methodology}

\section{Research Design}

This study employed a quantitative approach that mainly focused on the descriptive and inferential analyses as the research design. In order to clarify the theoretical background of the Consumers Behavioural Theory and the conceptual links of the demand for ride-hailing services, a documents analysis was carried out.

\section{Participants}

According to data from the Department of Statistics Malaysia (DOSM, 2020), there are 263 private institutions of higher learning located at the Klang Valley, Malaysia. The student population is roughly 29400 (Ministry of Higher Education [MOHE], 2020). By using the purposive sampling method and referring to Krejcie and Morgan's (1970) Table of Minimising Sample Size, a total of 383 from the student population were selected as the participants of this study.

Table 1 below shows the distribution of the participants in accordance with six demographic factors, namely, gender, age, nationality, level of studies, family monthly income and marital status. 
INTERNATIONAL JOURNAL OF ACADEMIC RESEARCH IN BUSINESS AND SOCIAL SCIENCES Vol. 10 , No. 12, 2020, E-ISSN: $2222-6990$ ๑ 2020 HRMARS

Table 1: Demographic Profile of the Participants

\begin{tabular}{llcc}
\hline Factor & $\begin{array}{l}\text { Demographic } \\
\text { variable }\end{array}$ & F & \% \\
\hline Gender & Male & 174 & 45.4 \\
& Female & 209 & 54.6 \\
\hline Age (years) & Below 21 & 68 & 17.8 \\
& $21-30$ & 184 & 48.0 \\
& $31-40$ & 92 & 24.0 \\
& $41-50$ & 39 & 10.2 \\
\hline Nationality & Malaysian & 186 & 48.6 \\
& Foreigner & 197 & 51.4 \\
\hline Level of studies & Certificate/Diploma & 66 & 17.2 \\
& Bachelor & 261 & 68.2 \\
& Masters & 48 & 12.5 \\
& PhD/Doctorate & 8 & 2.1 \\
\hline Family monthly income (RM) & Below 6000 & 12 & 3.1 \\
& $6000-7999$ & 112 & 29.2 \\
& $8000-9999$ & 118 & 30.8 \\
& 10000 and above & 141 & 36.9 \\
\hline Marital status & Single & 158 & 41.3 \\
& Married & 225 & 58.7 \\
\hline
\end{tabular}

From Table 1, there are 174 (45.4\%) male participants and 209 (54.6\%) female participants. Majority of the participants $(184,48 \%)$ aged $21-30$ years old, $92(24 \%)$ of the participants aged 31-40 years old, $68(17.8 \%)$ and 39 (10.2) of the participants aged below 21 years old and 41-50 years old respectively. In term of nationality, there is slightly higher number of foreigner students $(197,51.4 \%)$ in comparison with the local students (186, $48.6 \%)$. More than half of the participants $(261,68.2 \%)$ are studying in Bachelor degree programme. This is followed by Certificate/Diploma (66, 17.2\%), Masters (48, 12.5\%) and $\mathrm{PhD} /$ Doctorate $(8,2.1 \%)$ respectively. There are $141(36.9 \%)$ of the participants stated their family monthly earning more than RM10000, 118 (30.8\%) and 112 (29.2\%) participants with family monthly income of RM8000 - RM9999 and RM6000 - RM7999 respectively. Only 12 or $3.1 \%$ of them have a family monthly income below RM6000. Last but not least, 225 (58.7\%) of the participant are married and $158(41.3 \%)$ are still single.

\section{Data Collection}

The instrument of this research study was a set of questionnaires which was adapted from Sakunlertvattana (2016) as a tool for data collection. The questionnaires consisted four sections, namely, Section A: Demographic Factors; Section B: Level of Usage of Ride-hailing Services; Section C: Factors Related to the Demand for Ride-hailing Services; and Section D: The Demand for Ride-hailing Services. In order to determine the reliability and construct validity of the questionnaires, a pilot test was conducted. The results showed that the Cronbach's Alpha Coefficients for the five independent variables were relatively high: Tangible (0.88), Reliability (0.89), Comfort (0.91), Price (0.93) and Promotion (0.85). Similarly, the Cronbach's Alpha Coefficients for the dependant variable - The Demand for Ride-hailing Services also recorded high $(\alpha=0.91)$. From the aspect of construct validity, an items analysis was carried out and results showed that the questionnaires had reached the significant level 
at 0.05. In addition, Factor Analysis had further strengthened the construct validity of the questionnaires.

\section{Statistical Analysis}

In this study, both the Descriptive Analysis and Inferential Analysis were administrated in analysing the relationship between tangible, reliability, comfort, price, promotion and the demand for ride-hailing services. The statistical procedures aspects in this study involved Factor Analysis, Reliability Analysis, Linearity Test, Descriptive Analysis, Analysis of Difference, Correlative Analysis and Multiple Linear Regression Analysis.

\section{Results and Discussion}

\section{The Level of Demand for Ride-Hailing Services}

The first research question of this study is "What is the level of demand for ride-hailing services among private university students in Klang Valley, Malaysia?" To answer this research question, there were three items specifically designed to fulfil this purpose. The first item was asking the students on the frequency of usage on ride-hailing services in a month. The second item was asking on their monthly expenditure on ride-hailing services. The third item was intended to find out the total distance travelled using ride-hailing services in a month. The results are shown in Table 2.

\begin{tabular}{|c|c|c|}
\hline & $\begin{array}{c}\text { Mean } \\
(\bar{x})\end{array}$ & $\begin{array}{c}\text { Standard Deviation } \\
\text { (SD) }\end{array}$ \\
\hline $\begin{array}{l}\text { How frequent have you used ride- } \\
\text { hailing services in a month? }\end{array}$ & 13.28 & 1.44 \\
\hline $\begin{array}{l}\text { How much have you spent on ride- } \\
\text { hailing services in a month? }\end{array}$ & 130.91 & 12.74 \\
\hline $\begin{array}{l}\text { Roughly what is your total distance } \\
\text { travelled with the ride-hailing services } \\
\text { in a month? }\end{array}$ & 142.80 & 1.56 \\
\hline
\end{tabular}

Table 2 shows the mean scores for level of demand for ride-hailing services among private university students in the Klang Valley, Malaysia. In average, the students indicated that they travelled 13.28 times monthly using ride-hailing services $(\bar{x}=13.28, S D=1.44)$. In term of monthly expenditure, the students revealed that they spent RM130.91 on ride-hailing services $(\bar{x}=130.91, S D=12.74)$. The students also indicated that they had travelled roughly $142.80 \mathrm{~km}$ monthly using ride-hailing services $(\bar{x}=142.80, \mathrm{SD}=1.56)$. In summary, it is clear that the demand for ride-hailing services among private university students in the Klang Valley, Malaysia is relatively high. 
The Difference in Demand for Ride-Hailing Services in Accordance with Demographic Backgrounds

The second research question of this study is "Is there any difference on the demand of ridehailing services in accordance with the private university students' demographic backgrounds?" The results for this question are shown in Table 3, 4, 5, 6, 7 and 8.

Table 3: Mean Scores and T-Values Difference in Demand for Ride-Hailing Services in Accordance with Gender

\begin{tabular}{lcccccc}
\hline Gender & $\mathbf{N}$ & Mean $(\overline{\boldsymbol{x}})$ & SD & Std. Error Mean & $\mathbf{t}$ & Sig. \\
\hline Male & 174 & 15.05 & 1.63 & .122 & 23.347 & .000 \\
Female & 209 & 11.52 & 1.26 & .132 & & \\
\hline
\end{tabular}

Significant at the 0.05 level

From the T-Test results in Table 3, it is clear that there is a significant difference on the demand for ride-hailing services between the male and female private university students in Klang Valley, Malaysia $(t=23.347, \mathrm{df}=381, \mathrm{p}<.01$ ). The male students show higher degree of demand for ride-hailing services $(\bar{x}=15.05, S D=1.63)$ in comparison with the female students $(\bar{x}=11.52, S D=1.26)$. The results indicate that in average a male student used 15.05 times ride-hailing services monthly, while, the female student only used 11.52 times monthly.

Table 4: Mean Scores and F-Values Difference in Demand for Ride-Hailing Services in Accordance with Age Groups

ANOVA

\begin{tabular}{lccccc}
\hline Age groups & Sum of Squares & df & $\begin{array}{l}\text { Mean Square } \\
(\overline{\boldsymbol{x}})^{2}\end{array}$ & $\mathrm{~F}$ & Sig. \\
\hline Between & 1176.863 & 3 & 392.287 & & .813 \\
Groups & 969.234 & 379 & 2.5573 & 153.399 & \\
Within Groups & 2146.097 & 382 & & & \\
Total & & & & & \\
\hline
\end{tabular}

Table 4 shows the ANOVA Test results on the difference in demand for ride-hailing services in accordance with age groups. We can see that the significance value is 0.813 ( $p=$ $.813)$, which is greater than $0.05(P>.05)$. Therefore, there is no statistically significant difference on the mean times in demand for ride-hailing services between the different age groups $[F(3,379)=153.399, p>0.05]$. Hence, we can summarise that private university students from all ages have a similar degree of demand for ride-hailing services in Klang Valley, Malaysia.

Table 5: Mean Scores and T-Values Difference in Demand for Ride-Hailing Services in Accordance with Nationality

\begin{tabular}{lcccccc}
\hline Gender & $\mathbf{N}$ & Mean $(\bar{x})$ & SD & Std. Error Mean & t & Sig. \\
\hline Malaysian & 186 & 10.45 & 1.03 & .092 & -50.564 & .001 \\
Foreigner & 197 & 16.11 & 1.16 & .113 & & \\
\hline
\end{tabular}

Significant at the 0.05 level

Table 5 shows the mean scores and T-values difference in demand for ride-hailing services in accordance with the nationality of the private university students in Klang Valley, 
Malaysia. The results indicate that there is a significant difference on the mean times on demand for ride-hailing services between the Malaysian and foreign students ( $t=-50.564$, df $=381, p<.01)$. In this context, the foreign students show higher degree in demand for ridehailing services with the mean of 16.11 times monthly $(\bar{x}=16.11, S D=1.16)$, in comparison with the Malaysian students with only 10.45 times monthly $(\bar{x}=10.45, \mathrm{SD}=1.03)$.

Table 6: Mean Scores and F-Values Difference in Demand for Ride-Hailing Services in Accordance with Level of Studies ANOVA

\begin{tabular}{lccccc}
\hline Level of studies & Sum of Squares & df & $\begin{array}{c}\text { Mean Square } \\
(\overline{\boldsymbol{x}})^{2}\end{array}$ & F & Sig. \\
\hline Between & 1074.156 & 3 & 358.052 & \\
Groups & 1003.241 & 379 & 2.647 & 135.267 & .228 \\
Within Groups & 2077.397 & 382 & & & \\
Total & & & & \\
\hline
\end{tabular}

Table 6 shows the mean scores and F-values difference in demand for ride-hailing services in accordance with the level of studies of the private university students in Klang Valley, Malaysia. The results reveal that the significance value $(p=.228)$ is greater than 0.05 $(P>.05)$, therefore, there is no significant difference on the mean times in demand for ridehailing services among the students from difference level of studies $[F(3,379)=135.267, p>$ $.05]$. Hence, we can summarise that private university students from all level of studies have a similar degree of demand for ride-hailing services in Klang Valley, Malaysia.

Table 7: Mean Scores and F-Values Difference in Demand for Ride-Hailing Services in Accordance with Family Monthly Income

ANOVA

\begin{tabular}{lccccc}
\hline $\begin{array}{l}\text { Family monthly } \\
\text { income }\end{array}$ & $\begin{array}{c}\text { Sum of } \\
\text { Squares }\end{array}$ & df & $\begin{array}{c}\text { Mean Square } \\
(\overline{\boldsymbol{x}})^{2}\end{array}$ & $\mathrm{~F}$ & Sig. \\
\hline Between Groups & 542.331 & 3 & 180.777 & .002 \\
Within Groups & 1138.112 & 379 & 3.003 & 60.199 & \\
Total & 1680.443 & 382 & & & \\
\hline
\end{tabular}


Multiple Comparisons

Dependent Variable: Frequency of demand Tukey HSD

\begin{tabular}{lcccc}
\hline $\begin{array}{l}\text { (I) Income (RM) } \\
\text { (RM) }\end{array}$ & $(\mathrm{J})$ Income & $\begin{array}{c}\text { Mean difference } \\
(\mathrm{I}-\mathrm{J})\end{array}$ & $\begin{array}{c}\text { Std. } \\
\text { Error }\end{array}$ & Sig. \\
\hline Below 6000 & $6000-7999$ & -.043 & 1.831 & .568 \\
& $8000-9999$ & -.118 & 1.831 & .432 \\
& 10000 \& & $-4.830^{*}$ & 1.831 & .000 \\
above & & & & \\
\hline $6000-7999$ & Below 6000 & .043 & 1.831 & .568 \\
& $8000-9999$ & -.027 & 1.831 & .327 \\
& 10000 \& & -.103 & 1.831 & .183 \\
above & & .118 & 1.831 & .432 \\
\hline $8000-9999$ & Below 6000 & .027 & 1.831 & .327 \\
& $6000-7999$ & -.083 & 1.831 & .263 \\
& 10000 \& & $4.830^{*}$ & 1.831 & .000 \\
above & & .103 & 1.831 & .183 \\
\hline 10000 \& above & Below 6000 & .083 & 1.831 & .263 \\
& $6000-7999$ & & & \\
\hline
\end{tabular}

*The mean difference is significant at the 0.05 level

Table 7 shows the value of $F$ is 60.199, which reaches significance with a P-value of $0.002 \quad(P<.01)$. This means there is a statistically significant difference between the means of the different groups of students of the family monthly income variable $[F(3,379)=$ $60.199, p<.01$ ]. Subsequently, a Tukey Post Hoc Test shows that the students whose family monthly income of RM10,000 and above have a statistically significantly higher degree of demand for ride-hailing services in comparison with the students whose family monthly income is below RM6,000 ( $<$ <.01). In this case, the former group of students has shown 4.83 times more demand for ride-hailing services in comparison with the latter group of students. However, there are no statistically significant difference between the students whose family monthly income is below RM6,000 and other two groups of the students ( $P>.05)$.

Table 8: Mean Scores and T-Values Difference in Demand for Ride-Hailing Services in Accordance with Marital Status

\begin{tabular}{lcccccc}
\hline Gender & $\mathbf{N}$ & Mean $(\overline{\boldsymbol{x}})$ & SD & Std. Error Mean & $\mathbf{t}$ & Sig. \\
\hline Single & 158 & 14.35 & 1.53 & .102 & 20.105 & .022 \\
Married & 225 & 11.52 & 1.06 & .114 & & \\
\hline
\end{tabular}

Significant at the 0.05 level

Table 8 shows the T-Test results of the mean scores and T-values difference in demand for ride-hailing services in accordance with the students' marital status. The results show that there is a significant difference on the demand for ride-hailing services between the single and married private university students in Klang Valley, Malaysia $(t=20.105, d f=381, p<$ .05). The single students show higher degree of demand for ride-hailing services $(\bar{x}=14.35$, $\mathrm{SD}=1.53)$ in comparison with the married students $(\bar{x}=11.52, \mathrm{SD}=1.06)$. The results indicate 
that in average a single student demanded 14.35 times ride-hailing services monthly, while, the married student only demanded 11.52 times monthly.

\section{Hypothesis Testing}

The Relationship between Tangible, Reliability, Comfort, Price, Promotion and the Demand for Ride-Hailing Services

The third research question of this study is "Is there any significant relationship between tangible, reliability, comfort, price, promotion and the demand for ride-hailing services among private university students in Klang Valley, Malaysia?"

In order to measure the strength of the relationship between tangible, reliability, comfort, price, promotion and the demand for ride-hailing services, the researcher had referred to the Correlation Value Interpretation Table developed by Bartlett, Kontrlik and Hingins (2001). Besides, the parametric assumptions of the data set of this study had been addressed prior to the implementation of the Pearson Product-Moment Correlation to determine the significance of the relationships between the variables.

Table 9: Correlation Value Interpretation

\begin{tabular}{ll}
\hline Value $(\mathbf{r})$ & Strength \\
\hline $\pm 0.70-0.99$ & Very strong \\
$\pm 0.50-0.69$ & Strong \\
$\pm 0.30-0.49$ & Moderately strong \\
$\pm 0.10-0.29$ & Weak \\
$\pm 0.01-0.09$ & Very weak \\
\hline (Source: Bartlett, Kontrlik \& Hingins, \\
2001)
\end{tabular}

Table 10: Correlations between Tangible, Reliability, Comfort, Price, Promotion and the Demand for Ride-Hailing Services

\begin{tabular}{lcccccc}
\hline Variable & Demand & Tangible & Reliability & Comfort & Price & Promotion \\
\hline Demand & - & & & & & \\
Tangible & $.489^{* *}$ & - & & & & \\
Reliability & $.684^{* *}$ & .089 & - & & & \\
Comfort & .038 & $.413^{*}$ & -.084 & - & & \\
Price & $.645^{* *}$ & $.585^{*}$ & $-.518^{*}$ & $.431^{*}$ & - & \\
Promotion & $.610^{* *}$ & -.064 & $-.531^{* *}$ & -.058 & - & - \\
& & & & & $.445^{*}$ & \\
& & & & & $*$ & \\
\hline
\end{tabular}

**Correlation is significant at the 0.01 level.

*Correlation is significant at the 0.05 level.

From Table 10, it is found that there is a significant, positive and moderately strong relationship between tangible and the demand for ride-hailing services among the private university students in Klang Valley, Malaysia $(r=.489, n=383, p<.01)$. The positive significant relationship shows that any increase of tangible aspect will increase the demand for ridehailing services as well. Therefore, the first hypothesis of this study - " $\mathrm{H}_{1}$ : Tangible is positively related to the demand for ride-hailing services" is supported. The results are in line with the concept in the Consumers Behavioural Theory and SERQUAL Model that the purchase 
intention of a product or service is strongly linked with service quality (Loudon \& Della Bitta, 1993; Parasuraman et al., 1985; Kassarjian, 1982; Howard \& Sheth, 1969). The results are also consistent with the previous research findings conducted by Pradhan (2019), Pranav and Akshay (2018), Balachandran \& Hamzah (2017), Sakunlertvattana (2016), and Kosoff (2015).

A significant, positive and strong relationship found between reliability and the demand for ride-hailing services $(r=.684, n=383, p<.01)$. This means, a higher level of reliability will result in a higher level of the demand for ride-hailing services and vice versa. Therefore, the second hypothesis - " $\mathrm{H}_{2}$ : Reliability is positively related to the demand for ridehailing services" is supported. The results have further strengthened the concepts in the Consumers Behavioural Theory and SERQUAL Model. They are also concurred with the previous research findings (Nguyen-Phuoc et al., 2020; Ma et al., 2019; Wang et al., 2018; Balachandran \& Hamzah, 2017; Feng et al., 2017).

Interestingly, this study found no significant relationship between comfort and the demand for ride-hailing services $(r=.038, n=383, p>.05)$. Therefore, the third hypothesis " $\mathrm{H}_{3}$ : Comfort is positively related to the demand for ride-hailing services" is failed to be supported. The results are contradicted with the conceptual link that comfort is one of the factors influences customer's decision making on the purchase of a product or service (Loudon \& Della Bitta, 1993; Parasuraman et al., 1985; Kassarjian, 1982; Howard \& Sheth, 1969). They are also deviated from the findings of the previous researches (Nguyen-Phuoc et al., 2020; Ma et al., 2019; Wang et al., 2018; Balachandran \& Hamzah, 2017; Waruwu \& Adhiutama, 2017).

As for the factor of price, this study found that there is a significant, positive and strong relationship between price and the demand for ride-hailing services $(r=.645, n=383, p<$ .01). The positive significant relationship shows that a higher value in price can increase the level of demand for ride-hailing services and vice versa. Hence, the fourth hypothesis - " $\mathrm{H}_{4}$ : Price is positively related to the demand for ride-hailing services" is supported. These results also consistent with the findings from the previous studies carried out by Assegaff and Pranoto (2020), Nguyen-Phuoc et al. (2020), Prabowo (2018), Wang et al. (2018), Balachandran and Hamzah (2017), Septiani et al. (2017), and Feng et al. (2017).

Similarly, it is also found that there is a significant, positive and strong relationship between promotion and the demand for ride-hailing services $(r=.610, n=383, p<.01)$. This means any increase in promotion activities will result the increase in the demand for ridehailing services. Therefore, the fifth hypothesis - " $\mathrm{H}_{5}$ : Promotion is positively related to the demand for ride-hailing services" is supported. The results provide further support to the conceptual link that promotion activities influence customer's thinking and emotions while purchasing the products or services (Kotler \& Armstrong, 2012). This finding is also consistent with the findings from the previous studies (Nguyen-Phuoc et al., 2020; Pradhan, 2019; Prabowo, 2018; Balachandran \& Hamzah, 2017).

\section{The Predictor Factors of the Demand for Ride-Hailing Services}

A Multiple Linear Regression Analysis was conducted to ascertain the influence of predictor factors of tangible, reliability, comfort, price, and promotion on the demand for ride-hailing services. 
Table 11: Correlation and Multiple Regressions on the Demand for Ride-Hailing Services

\begin{tabular}{|c|c|c|c|}
\hline Independent variable & $r$ & Beta $(\beta)$ & Sig. \\
\hline Tangible & .489 & $.615^{* *}$ & .000 \\
\hline Reliability & .684 & $.784^{* *}$ & .000 \\
\hline Comfort & .038 & .012 & .324 \\
\hline Price & .645 & $.713^{* *}$ & .000 \\
\hline Promotion & 610 & $.658 * *$ & .000 \\
\hline $.577 \quad \mathrm{~F}=32.393 \quad R^{2}=$ & & $\begin{array}{l}\text { Adjusted } R^{2}= \\
.559 * *\end{array}$ & \\
\hline
\end{tabular}

a. Predictors: (Constant), of tangible, reliability, price, promotion

b. Dependent Variable: The demand for ride-hailing services

From Table 11, it is learned that all the factors statistically significantly predict the demand for ride-hailing services $[F(5,377)=32.393, p<.01]$, except for comfort $(p>.05)$. The combined influence of all the predictor factors explained $55.9 \%$ of the variance change in the demand for ride-hailing services $\left(R=.759\right.$, Adjusted $\left.R^{2}=.559, p<.01\right)$. Furthermore, reliability is found to be the best predictor factor of the demand for ride-hailing services $(\beta=$ $.784, p<.01)$. Tangible $(\beta=.615, p<.01)$, price $\quad(\beta=.645, p<.01)$ and promotion $(\beta=$ $.610, p<.01)$ are also good predictor factors of the demand for ride-hailing services. The results supported largely on the existing conceptual link of the demand for ride-hailing services and previous researches (Nguyen-Phuoc et al., 2020; Balachandran \& Hamzah, 2017; Sakunlertvattana, 2016).

\section{Conclusion and Implications}

The objective of this study is to examine the relationship between tangible, reliability, comfort, price, promotion and the demand for ride-hailing services in the context of the private universities in Klang Valley, Malaysia. The descriptive statistics of this study show that the level of demand for ride-hailing services among private university students in the Klang Valley, Malaysia is relatively high. T-Test shows significant difference in the demand for ridehailing services in accordance with gender, nationality and marital status. It is clear that there is a higher degree of demand for ride-hailing services from the male, foreigner and single students. Similarly, the ANOVA Analysis shows that the students whose family monthly income of RM10,000 and above have a statistically significantly higher degree of demand for ride-hailing services in comparison with the students whose family monthly income is below RM6,000.

The inferential statistics of this study show that there is a significant, strong and positive relationship between tangible, reliability, price and promotion and the demand for ride-hailing services respectively. Furthermore, reliability shows the strongest relationship with the demand for ride-hailing services. In addition, Regression Analysis confirms that reliability is the most dominant predictor factor of the demand for ride-hailing services. Tangible, price and promotion are also found to be good predictor factors to the demand for ride-hailing services. Interestingly, comfort is the only factor which has neither relationship nor influence on the demand for ride-hailing services.

The findings of this study have implications not only for the ride-hailing industry and its users but also for the entire student's population of Malaysia especially those from 
institutions of higher learning. The dominance effect of reliability, price, promotion and tangible on the demand for ride-hailing services emphasize the need for the industry players to initiate a greater effort in ensuring the high service quality at all times. They should also be responsible in making sure a competitive pricing, besides putting in greater effort in promoting the services among the private university students or perhaps even in the broader community groups.

Drawing on from the discussion above, gives the following expectation if the demand of ride-hailing services in the Klang Valley, Malaysia is to be enhanced. First of all, from the perspective of reliability, in which if the service providers could implement some sort of convincing policies or practices that offer reliable services to their users in term of punctuality, waiting time, arrival at destination, journey length, communications, and scheduled routes. How far could the service providers in ensuring the community towards this positive practice or consistency will result a great impact on the demand for ride-hailing services.

Secondly, the ride-hailing service providers should consider fixed and transparent pricing in accordance with zone or journey length, and category of users. In this endeavour, the service providers should provide a clear price list at their Apps without any hidden charges. Besides, they should also offer more affordable pricing for students, senior citizens, handicapped and other under privileged groups of peoples.

Thirdly, from the perspective of promotion, it is wise for the ride-hailing service providers to continuously having promotion activities to boost up their sales. Providing ediscount voucher for instance, is one of the effective strategies that can attract more users especially those tech-savvy and younger generation. This innovative way not only will trigger users' interest to adopt for new technology like using Apps for redemption of the e-discount voucher, but also a motivating factor for the demand for ride-hailing services.

Last but not least, from the perspective of tangible that involves the physical facilities and physical dimensions of the service. In order to provide convincing high standard of service quality, the ride-hailing service providers need to ensure they have new, modern, safe, visually appealing and well cleaned vehicles ready to serve everyone. Besides, all drivers are neat in appearance. Their Apps should be convenient and user-friendly at all times.

As this study is a study investigating factors that related to the demand for ride-hailing services with the focus on the private university students in Klang Valley, Malaysia, therefore, the results may not be able to generalise to the entire Malaysian population. Hence, there is ample room for future research to be carried out at the broader area and society of Malaysia, especially those under privileged and low income frequent travellers, where their purchasing power can be expected to be low. Such research efforts would allow greater generalizations to be made and facilitate the efforts in increasing the demand for ride-hailing services throughout the nation. Other potential influencing factors on the demand for ride-hailing services should also be considered for future studies, inclusive of but not limited to, the aspects of assurance, empathy and responsiveness from the SERVQUAL Model, government transportation policies on e-hailing and one's willingness to spend on ride-hailing services.

\section{Theoretical and Contextual Contribution}

The ultimate contribution of the findings of this study is threefold. First and foremost, the findings of this study are more focused and specified in the context of private university students in comparison with the existing literature which are more focused on the general public in nature. Although this study has supported most of the existing findings, but, they are in a different sequent. In this context, reliability is the most dominant factor influencing 
the demand for ride-hailing services. Followed by price, promotion and tangible. In contrast, price is arguably the most dominant factor at the existing literature. Secondly, this study has proven that not all the factors as argued at the existing literature that have significant relationship or influence on the demand for ride-hailing services. This study shows strong evidence that comfort neither has significant relationship nor influence on the demand for ride-hailing services. In the matter of fact, this noticeable finding has contradicted and challenged the existing conceptual link in the Consumers Behavioural Theory. Subsequently, this finding is worth- trusty to be reviewed to the existing model for the demand for ridehailing services. Lastly, this study has revealed that male, single, foreign students with monthly family income of RM10,000 and above have a higher degree on the demand for ridehailing services. These are the important and significant demographics information that could be possibly added to enrich the existing literature on the demand for ride-hailing services.

\section{References}

Assegaff, S. B., \& Pranoto, S. O. (2020). Price determines customer loyalty in ride-hailing services. American Journal of Humanities and Social Sciences Research, 4(3), 453-463. https://www.researchgate.net/publication/340236752_Price_Determines_Customer_L oyalty_in_Ride-Hailing_Services

Balachandran, I., \& Hamzah, I. (2017). The influence of customer satisfaction on ride-sharing services in Malaysia. International Journal of Accounting \& Business Management, 5(2), 184-196. https://www.ftms.edu.my/journals/pdf/IJABM/Nov2017/184-196.pdf

Bartlett, J., Kontrlik, J., \& Hingins, G. (2001). Organizational research: Determining appropriate sample size in survey research. Information Technology, Learning, and Performance Journal, 19(1), 43-50. https://www.opalco.com/wpcontent/uploads/2014/10/Reading-Sample-Size1.pdf

Clewlow, R. R., Mishra, G.S., Affiliate, R., \& Kulieke, S. (2017). Disruptive transportation: The Adoption, Utilization, and Impacts of Ride-Hailing in the United States for media or other inquiries. Institute of Transportation Studies, University of California, Davis. Retrieved from https://htv-prod-media.s3.amazonaws.com/files/ucd-ride-hailing-report1508296368.pdf

Department of Statistics Malaysia. (2020). Services statistics education. https://www.dosm.gov.my/v1/index.php?r=column/cone\&menu_id=ZmpBKzc4T2pFTX VNUW1NCHRFMHhGQT09

Feng, G., Kong, G., \& Wang, Z. (2017). We are on the Way: Analysis of on-demand ride-hailing systems. SSRN Electronic Journal. https://doi.org/10.2139/ssrn.2960991

Howard, J. A., \& Sheth, J. N. (1969). The Theory of Buyer Behaviour. John Wiley and Sons Inc. Kassarjian, H. H. (1982). The development of Consumer Behavior Theory. In A. Mitchell \& A. Abor (Eds), Advances in Consumer Research (pp. 20-22). Association for Consumer Research. https://www.acrwebsite.org/volumes/5894/volumes/v09/NA-09

Kosoff, M. (2015). Uber turns five today - here's how it took over the world in just a few years. Business Insider. https://www.businessinsider.com/how-uber-took-over-theworld-2015-6? IR=T

Kotler, P., \& Armstrong, G. (2012). Principle of marketing (14th ed.). Pearson Prentice Hall. Krejcie, R., \& Morgan, D. (1970). Determining sample size for research activities. Educational and Psychological Measurement, 30, 607-610.

https://doi.org/10.1177/001316447003000308 
Litman, T. (2008). Valuing transit service quality improvements. Journal of Public Transportation, 43-64. http://doi.org/10.5038/2375-0901.11.2.3

Loudon, D. L., \& Bitta, D. A. J. (1993). Consumer behavior: Concepts and applications. McGrawHill College. https://doi.org/10.1080/00913367.1979.10673299

Lovelock, C. H., \& Wright, L. (2002). Principles of service marketing and management, Prentice Hall.

Ma, L., Zhang, X., Ding, X., \& Wang, G. (2019). Risk perception and intention to discontinue use of ride-hailing services in China: Taking the example of DiDi Chuxing. Transportation Research Part F: Traffic Psychology and Behaviour, 66, 459-470. https://doi.org/10.1016/j.trf.2019.09.021

Matzler, K., Wurtele, A., \& Renzl, B. (2006). Dimensions of price satisfaction: A study in the retail banking industry. International Journal of Bank Marketing, 24(4), 216-231. https://doi.org/10.1108/02652320610671324

McKnight, C.E., Pagano, A.N., \& Paaswell, R.E. (1985, April 16-19). Using quality to predict demand for special transportation [Paper presentation]. International Conference on Travel Behaviour, Noordwijk, the Netherlands. https://trid.trb.org/view/651172

Ministry of Higher Education Malaysia. (2020, April 10). Higher Educational Statistics. https://www.moe.gov.my/muat-turun/penerbitan-dan-jurnal/terbitan/bukuinformasi/2722-quick-facts-2019/file

Nguyen-Phuoc, D.Q., Su, D.N. Kim-Tran, P.T., Diem-Trinh, T.L., \& Johnson, L.W. (2020). Factors influencing customers loyalty towards ride-hailing taxi services - A case study of Vietnam. Transportation Research Part A: Policy and Practice, 134(C), 96-112. https://doi.org/10.1016/j.tra.2020.02.008

Parasuraman, A., Zeithaml, V., \& Berry, L. L. (1985). A conceptual model of service quality and its implications for future research. Journal of Marketing, 49(4), 41-50. https://doi.org/10.1177/002224298504900403

Parasuraman, A., Berry, L. L., \& Zeithaml, V. (1991). Refinement and reassessment of the SERVQUAL Scale. Journal of Retailing, 67(4), 420-450.

https://www.researchgate.net/publication/304344168_Refinement_and_reassessment _of_the_SERVQUAL_scale

Pham, A., Dacosta, I., Jacot-Guillarmod, B., Huguenin, K., Hubaux, J. P., Hajar, T., Gligor, V., \& Tramer, F. (2017). Private Ride: A Privacy-Preserving and Secure Ride-Hailing Service. Proceedings on Privacy Enhancing Technologies, De Gruyter Open, 2017 (2), 38-56. https://hal.archives-ouvertes.fr/hal-01401879/document

Prabowo, Y. (2018). Uber, Go-Jek, Grab: What do People in Indonesia Actually Want from RideHailing Apps? aCommerce. https://ecommerceiq.asia/cp-ride-hailing-apps-in-indonesia/

Pradhan, D. (2019). How Grab is becoming an everyday, everything app in Southeast Asia. Entrepreneur Asia Pacific. https://www.entrepreneur.com/article/334690

Pranav, P., \& Akshay, J. (2018). Ride-hailing service market by service type (E-hailing, car sharing, car rental, and station-based mobility), vehicle type (two-wheeler, threewheeler, four-wheeler, and others), location (urban and rural), and end user (institutional and personal): Global opportunity analysis and industry forecast, 2018 - 2025. Allied Market Research. https://www.alliedmarketresearch.com/ride-hailing-service-market

Sadowsky, N., \& Nelson, E. (2017). The impact of ride-hailing services on public transportation use: A discontinuity regression analysis (Economics Department Working Paper Series 13). https://digitalcommons.bowdoin.edu/econpapers/13 
Sakunlertvattana, W. (2016). Factors influencing consumer brand choice of top 3 taxi booking mobile applications in Bangkok: Uber, Grabtaxi and Easy Taxi [Master's thesis, Bangkok University]. The Graduate School of Bangkok University Master's Monographs Digital Collection.

http://dspace.bu.ac.th/bitstream/123456789/1971/1/Watchareebhorn_saku.pdf

Septiani, R., Handayani, P. W., \& Azzahro, F. (2017). An empirical examination of factors affecting the behavioral intention to use online transportation service: Case study of GRAB. In 2017 International Conference on Advanced Computer Science and Information Systems (ICACSIS) (pp. 93-98). https://doi.org/10.1109/ICACSIS.2017.8355017

The Star. (2019). Ride-hailing - A booming industry. The Star Business. https://www.thestar.com.my/business/business-news/2019/08/24/ride-hailing---abooming-industry

Virvilaite, R., Saladiene, V., \& Skindaras, D. (2009). The Relationship between price and loyalty in services industry. Inzinerine Ekonomika-Engineering Economics, 3, 96-104. https://www.researchgate.net/publication/228350111_The_Relationship_between_Pri ce_and_Loyalty_in_Services_Industry

Wang, Y., Wang, S., Wang, J., Wei, J., \& Wang, C. (2018). An empirical study of consumers' intention to use ride-sharing services: using an extended technology acceptance model. Transportation, 47, 397-415. https://doi.org/10.1007/s11116-018-9893-4

Waruwu, J. J., \& Adhiutama, A. (2017). Analysis of motor sharing (online transportation) customer in Bandung case study: go-jek in bandung. Journal of business and management, 6(1), 143-159. https://core.ac.uk/download/pdf/304293917.pdf

Zeithaml, V., Bitner, M.J., \& Gremler, D.D. (2018). Service marketing: Integrating customer focus across the firm (7th ed.). McGraw-Hill Education. 